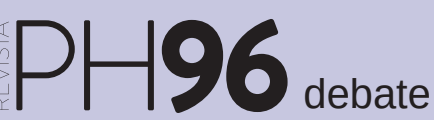

a debate Memoria democrática en la construcción de la historia y el patrimonio

| coordina Josefina Cuesta Bustillo

\title{
Entre la memoria plural y la memoria crítica
}

Olivia Muñoz-Rojas | ensayista e investigadora independiente

URL de la contribución <www.iaph.es/revistaph/index.php/revistaph/article/view/4304>

\section{Sobre el concepto de memoria democrática}

Antes de abordar algunas de las cuestiones planteadas en la propuesta de debate, me gustaría reflexionar brevemente sobre qué entendemos por memoria democrática. La orientación de las políticas de memoria dependerá de cómo entendamos este concepto. ¿Hablamos de una memoria construida democráticamente en el presente con la participación de toda la ciudadanía, desde una "pluralidad de visiones y posibilidades de apropiaciones diversas"? (JELIN, 2014) ¿Hablamos de una memoria que desde el presente aplica las exigencias de una democracia sobre el pasado? ¿O hablamos de una suerte de combinación de ambos significados? Si nos decantamos por el primero, asumimos que todas las memorias -incluso aquellas que no contribuyeron al desarrollo de una sociedad democrática-, en la medida en que siguen socialmente vivas, deben formar parte de la memoria colectiva de un país. Si lo hacemos por el segundo significado, reclamamos una memoria crítica que se desprende de los episodios antidemocráticos del pasado y reivindica aquellos que contribuyeron al desarrollo de la democracia. Una combinación de ambos significados buscaría un compromiso entre, por una parte, una memoria construida por toda la ciudadanía, incluso aquella que se identifica con sucesos antidemocráticos del pasado; y, por otra parte, lo fundamental de reforzar los valores democráticos, resaltando su continuidad histórica o, dicho en palabras de Josefina Cuesta Bustillo, "privilegiando genealogías democráticas".

En el contexto español, el concepto de memoria democrática se asocia, sobre todo, con la reivindicación de la memoria de los vencidos. Esto es, la memoria de la II República, de la lucha contra el bando nacional durante la Guerra Civil, del exilio y las víctimas de la represión franquista, de la lucha clandestina por la democracia y, finalmente, la memoria de la Transición. Es interesante señalar que, en el debate internacional, se trata de un concepto frecuentemente asociado al caso español. En otros contextos, hallamos conceptos como el de memoria pública que, de acuerdo a algunos autores, designa un espacio intermedio de negociación entre la memoria oficial o memoria de Estado y la memoria colectiva de una minoría o grupo social en particular (MICHEL, 2015).

\section{¿De quién es tarea construir la memoria colectiva?}

En todo caso, todo proceso de construcción de la memoria en una democracia debe ser una tarea colectiva de la que participan una pluralidad de actores (historiadores, expertos en patrimonio, las diferentes administraciones, asociaciones de la sociedad civil, etc.). Estamos ante un proceso dinámico, cambiante. La memoria colectiva como la memoria individual- es algo vivo, en constante revisión, en función de las experiencias e intereses del presente.

Al mismo tiempo, es innegable que sería deseable y útil social y políticamente que, en el caso que nos ocupa, existiera un mínimo consenso sobre la memoria oficial del pasado reciente que incluye la Guerra Civil, la dictadura y la transición a la democracia. Si bien el 20 de noviembre de 2002 todos los partidos condenaron en sede parlamentaria el alzamiento del 18 de julio de 1936 y se comprometieron a honrar a todas las víctimas de la Guerra Civil (CUÉ, 2002), hay partidos que se han desmarcado de dicha condena y compromiso desde entonces. Una declaración consensuada por el conjunto de los representantes políticos que reconociera las trágicas consecuencias de la Guerra Civil, condenara el régimen franquista por su carácter antidemocrático y reconociera, asimismo, la complejidad (¿incompletud?) de la Transición constituiría un paso adelante. Hay, asimismo, cuestiones concretas que, desde el punto de vista de los 
Derechos Humanos, parecen inapelables y que debieran formar parte de ese consenso. Entre ellas, el apoyo de las administraciones a los ciudadanos que desean localizar los restos de sus familiares asesinados por la dictadura.

Sin embargo, es posible que la pretensión de legislar exhaustivamente sobre el conjunto de aspectos simbólicos y materiales que conforman la memoria colectiva de un episodio tan complejo como una guerra civil y una experiencia tan polarizadora como una dictadura vaya en detrimento de la dinamicidad y crítica permanente que una democracia exige (sobre la relación entre ley y memoria ver, entre otros, MISZTAL, 2001). Dicha pretensión ofrece, asimismo, argumentos a quienes niegan la necesidad de desarrollar políticas de memoria y las tildan de partidistas y manipuladoras.

\section{¿'Patrimonializar' la memoria democrática?}

En consecuencia, más que desprenderse del pasado antidemocrático, conviene sumar la memoria de todas aquellas personas, entidades, etc. que lucharon por (re) establecer la democracia. En cualquier sistema democrático, las administraciones tienen la responsabilidad de fomentar los principios y valores democráticos. Una manera de hacerlo es, precisamente, recuperando y poniendo en valor las reivindicaciones y las luchas del pasado reciente que contribuyeron al legado democrático actual, en nuestro caso, desde la lucha contra la imposición de un sistema antidemocrático durante la Guerra Civil hasta la lucha de las mujeres durante la Transición. Parece evidente que, en el caso español, a raíz del carácter pactado que tuvo la Transición, esta labor ha sido insuficiente: si apenas se ha tocado la memoria de los vencedores desde entonces, tampoco se le ha dado a la memoria de los vencidos una presencia y visibilidad equivalentes. Desde las instituciones y la sociedad civil existe un margen de trabajo amplísimo en este sentido y, si se enfoca como una labor de naturaleza más constructiva que destructiva, es posible que genere menos resistencias.

Por ello, respondiendo a la pregunta sobre los símbolos franquistas en el espacio público y tal y como he expuesto en anteriores ocasiones, en términos generales, considero más útil para la convivencia democrática la realización de intervenciones críticas y artísticas de contextualización y resignificación de dichos símbolos que su retirada, así como la creación de nuevos memoriales democráticos. Como dice Cuesta Bustillo en el texto introductorio a este debate, no es lo mismo jugar o pasear en la plaza de la División Azul que en la plaza de la Libertad. Pero quizá es posible hacerlo en la plaza de la Libertad sabiendo que, no hace tanto, fue la plaza de la División Azul. Y que ésta no es un equipo de fútbol (como podrían pensar muchos niños hoy), sino una unidad de voluntarios españoles que se alistaron para luchar con los nazis durante la Segunda Guerra Mundial. De cualquier modo, es necesario abordar caso por caso, asumiendo que la controversia y la dilación en el proceso de toma de decisión sobre cada uno de los elementos materiales e inmateriales que nos lega ese pasado incómodo forman parte del trabajo de memoria que debemos realizar como sociedad. En este trabajo es fundamental nutrirse de las experiencias de otros países con retos similares. A fin de cuentas, podría decirse que la memoria democrática forma parte de un patrimonio global.

\section{BIBLIOGRAFÍA}

- CUÉ, C. E. (2002) El PP condena el golpe de Franco y promete honrar a todas las víctimas de la Guerra Civil. El País, 21 noviembre de 2002

- JELIN, E. (2014) Memoria y democracia. Una relación incierta. Revista Mexicana de Ciencias Políticas y Sociales [en línea desde 2015], vol. 59, n. ${ }^{\circ} 221$, pp. 225-41 <http://www. revistas.unam.mx/index.php/rmcpys/article/view/47707> [Consulta: $13 / 11 / 18]$

- MICHEL, J. (2015) Mémoire publique et mémoire collective de l'esclavage. Revue indisciplinaire de sciences sociales. Espacestemps.net [en línea], 12 de mayo de $2015<$ https://www. espacestemps.net/articles/memoire-publique-et-memoire-co Ilective-de-lesclavage/> [Consulta: 12/11/18]

- MISZTAL, B. A. (2001) Legal Attempts to Construct Collective Memory: The Necessity and Difficulties of Aiming for Both Truth and Solidarity. Polish Sociological Review, n. ${ }^{\circ}$ 133, 2001, pp. $61-75$ 